\title{
Predicting effect of emotional-social intelligence on academic achievement of nursing students
}

\author{
A Alenezi, ${ }^{1} \mathrm{PhD}$; M S Moustafa Saleh, ${ }^{1,2} \mathrm{PhD}$; R A Gawad Elkalashy, ${ }^{1,3} \mathrm{PhD}$ \\ ${ }^{1}$ Department of Nursing, College of Applied Medical Science, Shaqra University, Saudi Arabia \\ ${ }^{2}$ Department of Nursing, Nursing Administration, Faculty of Nursing, Zagazig University, Egypt \\ ${ }^{3}$ Department of Nursing, Medical Surgical Nursing, Faculty of Nursing, Menoufia University, Egypt
}

Corresponding author: A Alenezi (atta@su.edu.sa)

\begin{abstract}
Background. Academic achievement refers to the extent to which a learner, instructor or institution has accomplished their short- or long-term educational goals. There are inconclusive results about the individual factors that successfully predict academic performance. Emotional intelligence has been a popular topic in the field of higher educational learning. Several research reports have shown that emotional intelligence is one of the factors that successfully predicts students' academic achievement.

Objectives. To examine the relationship between emotional-social intelligence (ESI) and self-reported academic achievement among nursing students. Methods. A descriptive-comparative approach was used. The study was carried out on 127 nursing students from different academic levels. The study used two tools, namely an ESI questionnaire and an academic achievement scale.

Results. The females had statistically significant higher means than the males in their scores on the ESI questionnaire $(p=0.042)$ and interpersonal competencies $(p=0.003$ ). There were positive correlations between ESI score, its five components and students' self-reported academic achievement. Conclusion. The outcome of this study suggests that educational planners and academicians should embrace emotional intelligence-developing courses at college and university levels.
\end{abstract}

Afr J Health Professions Educ 2020;12(3):144-148. https://doi.org/10.7196/AJHPE.2020.v12i3.1365

Emotional-social intelligence (ESI) is known to improve and enhance the learning process, and it is a popular topic of debate in the field of nursing education. Emotional intelligence is a concept that has received increased attention in in academic circles. Emotional intelligence helps students excel, and it also can help teachers to effect and excel in their profession. ${ }^{[1]}$ The development of emotional intelligence will increase academic achievement and ensure that new nursing entrants to the profession have the abilities, knowledge and skills to provide efficient and effective nursing care. Academic achievement refers to how well students accomplish their tasks and studies. ${ }^{[2]}$ To achieve this, nurse educators must determine the areas that require improvement in relation to ESI, and assess the educational needs of nursing students. ${ }^{[3]}$

A previous study reported a significant relationship between emotional intelligence and undergraduate students' academic achievement at the MidWestern University in the USA. ${ }^{[4]}$ Similarly, a study from Pakistan reported that students with high emotional intelligence showed better academic performance than students with low emotional intelligence. ${ }^{[5]}$ Previous research has also confirmed a significant correlation between emotional intelligence and self-efficacy with academic achievement among Nigerian university students. ${ }^{[6]}$ Furthermore, Sünbül and Aslan ${ }^{[7]}$ concluded a similar relationship between emotional intelligence and academic achievement among 312 education students in Konya, Turkey. Moreover, there is a significant body of research that suggests ESI and other non-traditional measures are just as predictive of academic success as traditional IQ tests. ${ }^{[8]}$

Even though there is significant evidence to support the influence of emotional intelligence on academic achievement, very few studies have explored this motivational mechanism in nursing students in Saudi Arabia. Hence, this research attempts to shed some light on the relationship between emotional intelligence and academic success among Saudi undergraduate nursing students. Results of the present study could be used by nursing educators to include the concept of emotional intelligence in their students' curriculum and classrooms to help them cope better with educational and social pressures.

\section{Methods}

The researchers used a descriptive-comparative approach. The respondents in this study were nursing students from the University of Shaqra (Kingdom of Saudi Arabia). Participants were identified via convenience sampling, and 127 male and female nursing students from year 2 to year 4, enrolled in the academic year 2018 - 2019 at the Colleges of Applied Medical Sciences in Shaqra, participated in the study. This research used two tools to collect data: an ESI questionnaire, developed by Bar-On et al., ${ }^{[9]}$ and an academic achievement scale.

The ESI questionnaire was composed of two parts: part one consists of a personal characteristics data sheet, including a code number, age, sex, and parents' occupation; part two consists of 53 competencies under 5 components specific for undergraduate nursing students: (i) intrapersonal competencies (16 competencies) grouped under 5 subscales: self-esteem, self-awareness, assertiveness, independence and self-actualisation; (ii) interpersonal competencies (13 competencies) grouped under 3 subscales: empathy, social responsibility and personal relationships; (iii) adaptability ( 9 competencies) grouped under 3 subscales: reality testing, flexibility and problem-solving; (iv) stress management (8 items) grouped under 2 subscales: stress tolerance, and impulse control. In addition, general mood (7 items) is grouped under 2 subscales: optimism and happiness. 
The instrument uses a 5-point Likert scale, with item response scores ranging from 1 (not true for me) to 5 (true for me). The total score for each student (265) was calculated and converted into a $\%$ score, and was categorised into unsatisfactory if the score was $<60 \%$ and satisfactory if the score was $\geq 60 \%$. The researchers tested the reliability of the questionnaire and found that this questionnaire had high internal consistency (Cronbach's a coefficients were $0.980,0.850,0.880,0.840$ and 0.870 for intrapersonal competencies, interpersonal competencies, adaptability, stress management and general mood, in that order).

In terms of determining the academic achievement of the students, a tool was constructed and developed by researchers based on the review of literature, as per Zimmerman and Schunk. ${ }^{[10]}$ Students indicated their level of agreement using the scale $0=$ very little efficacy, $1=$ little, $2=$ moderate, $3=$ a lot and $4=$ quite a lot. This scale consisted of 45 self-report statements to capture respondents' views of their academic achievement. The tool was divided into five main categories as: academic performance; extracurricular activities; student's interaction; student's behaviour; and student's attendance. Each category has nine statements, and the scores for each category were summed to give a total score and categorised into lower academic achievement $(0-<60)$, moderate academic achievement $(60-<120)$ and higher academic achievement $(120-180)$.

The higher score means the greater the student's academic achievement. A high internal consistency was observed by the researchers, through tested Cronbach a coefficients to measure the reliability of the tool in this study guided by Sun et al..$^{[11]}$ and Tavatol and Dennis. ${ }^{[12]}$ The reliability of five main categories of academic achievement mentioned before $(0.935,0.860,0.860$, $0.935,0.900)$ correspond.

A pilot study with 11 randomly selected nursing students (10\% of the study sample) was performed to ensure applicability, clarity and feasibility of the instruments. The students took around 15 - 20 minutes to complete the questionnaire. No modifications were made, and the results of the pilot study were included in the study results.

Ethical approval (ref. no. E1032) was given by the Deanship of Scientific Research, Shaqra University (Saudi Arabia). The study was conducted at the College of Applied Medical Sciences in Shaqra. The students' participation in the study was voluntary and all participants were assured that their marks would not be affected if they did not participate in the study, and that they could withdraw from the study at any time.

\section{Statistical design}

The data collected were computerised, revised, categorised, tabulated, analysed and presented in descriptive and associated statistical form using Statistical Package for Social Sciences version 20 (IBM Corp., USA). The data were tested by numerical data expressed as mean (standard deviation (SD)). Qualitative data were expressed as frequency and percentage. Difference between quantitative variables was tested by using the independent $t$-test and one-way analysis of variance test. The correlations between different numerical variables were tested using Pearson's correlation test. $P \leq 0.05$ was considered significant, and highly significant at $p \leq 0.001$.

\section{Results}

Table 1 contains demographic traits of the students, and shows that $66.1 \%$ of the participants were male, and the mean (SD) age of participants was 20.7 (2.4), with $57.5 \%>20$ years old. The majority (83.5\%) reported a high grade point average score. Most of the students' parents were highly educated
(62.2\% and $54.3 \%$ of the mothers and fathers of the students, respectively, were university graduates).

Fig. 1 describes categories of ESI among participants: it shows that more than two-thirds of the study sample had a satisfactory level for emotional intelligence (66.9\%), as compared with $33.1 \%$ who had an unsatisfactory level of emotional intelligence.

Table 2 illustrates that there were significant statistical differences between male and female students regarding their scores on the ESI questionnaire and interpersonal competencies score, in favour of females, with a mean difference of 9.52 and 4.65 , respectively, and $p$-values of 0.003 and 0.042 , respectively, at a $95 \%$ confidence interval.

\begin{tabular}{ll}
\multicolumn{2}{l}{ Table 1. Sociodemographic characteristics of sample $(\mathbf{N}=\mathbf{1 2 7})$} \\
\hline Characteristic & $\boldsymbol{n}(\%)$ \\
\hline Gender & \\
Male & $84(66.1)$ \\
Female & $43(33.9)$ \\
Age, years & \\
$>20$ & $54(42.5)$ \\
$\leq 20$ & $73(57.5)$ \\
Mean (SD) & $20.73(2.42)$ \\
Academic level & \\
Year 2 & $57(44.9)$ \\
Year 3 & $43(33.9)$ \\
Year 4 & $27(21.3)$ \\
GPA & \\
Low & $12(9.4)$ \\
Average & $9(7.1)$ \\
High & $106(83.5)$ \\
Level of mother's education & \\
Illiterate & $3(2.4)$ \\
Basic & $23(18.1)$ \\
Intermediate & $22(17.3)$ \\
Higher education & $79(62.2)$ \\
Level of father's education & \\
Illiterate & $1(8)$ \\
Basic & $24(18.9)$ \\
Intermediate & $33(26)$ \\
Higher education & $69(54.3)$ \\
SD = standard deviation; GPA = grade point average. & \\
&
\end{tabular}

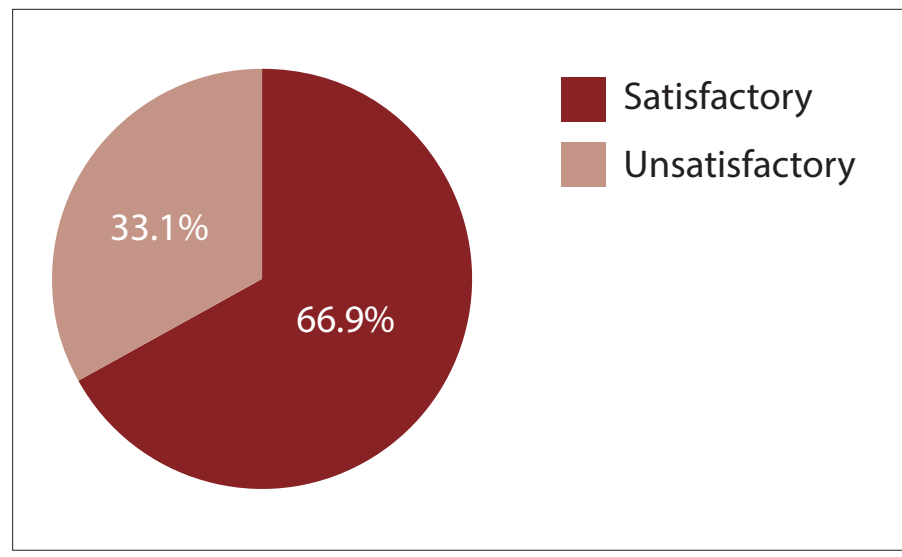

Fig. 1. Distribution of emotional-social intelligence levels among study sample. 
Fig. 2 describes levels of academic achievement among the study sample, and demonstrates that it was high in $70 \%$ of participants, compared with $8.7 \%$ of the participants whose academic achievement was low.

Table 3 explains the difference in academic achievement between male and female students. However, there were no significant differences between the two sexes regarding total mean score of self-reported academic achievement or its dimensions.

Table 4 reveals the results of analysis of variance tests for the relationship between the level of education of students' parents and ESI questionnaire scores, and shows a significant difference between parents' education with regard to ESI score $(p \leq 0.05)$.

Additional results found a low degree of positive correlation between age and ESI score ( $p=0.012$ and $r=0.223$ ).

Table 5 shows that there is an association between ESI score and academic achievement score. Also, all ESI questionnaire dimensions (intrapersonal and interpersonal competencies, adaptability, stress management and general mood) separately correlated positively with academic achievement score.

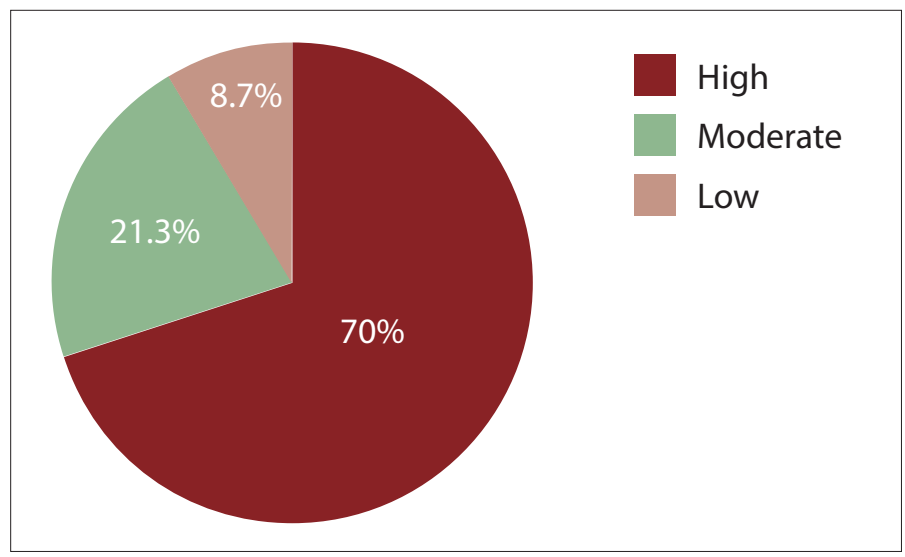

Fig. 2. Academic achievement levels among study sample.
Table 4. The relationship between level of education of students' parents and ESI questionnaire score

\begin{tabular}{|c|c|c|c|}
\hline \multirow[b]{2}{*}{ Variables } & \multirow[b]{2}{*}{ Mean (SD) } & \multicolumn{2}{|c|}{ ANOVA } \\
\hline & & $F$-value & $p$-value ${ }^{*}$ \\
\hline \multicolumn{4}{|c|}{ Mother's educational levels } \\
\hline Illiterate & $227.56(11.33)$ & 9.40 & 0.004 \\
\hline Basic & $232(15.12)$ & & \\
\hline Intermediate & $231.77(13.91)$ & & \\
\hline Higher education & $247.33(12.23)$ & & \\
\hline \multicolumn{4}{|c|}{ Father's educational levels } \\
\hline Illiterate & $239.48(14.37)$ & 12.5 & 0.001 \\
\hline Basic & $242.62(17.52)$ & & \\
\hline Intermediate & $240.12(16.35)$ & & \\
\hline Higher education & $254.46(15.21)$ & & \\
\hline
\end{tabular}

Table 5. Correlation coefficient between the ESI score, its dimensions and academic achievement score $(N=127)$

\begin{tabular}{lll}
\hline Variables & $p$-value $^{*}$ & $\boldsymbol{r}$-value \\
\hline ESI and academic achievement scores & 0.00 & 0.446 \\
$\begin{array}{l}\text { Intrapersonal competencies and academic } \\
\text { achievement scores }\end{array}$ & 0.00 & 0.440 \\
$\begin{array}{l}\text { Intrapersonal competencies and academic } \\
\text { achievement scores }\end{array}$ & 0.00 & 0.379 \\
$\begin{array}{l}\text { Adaptability and academic achievement scores } \\
\text { Stress management and academic achievement }\end{array}$ & 0.00 & 0.385 \\
$\begin{array}{l}\text { scores } \\
\text { General mood score and academic achievement } \\
\text { scores }\end{array}$ & 0.00 & 0.236 \\
${ }^{*} p \leq 0.01$. & & 0.407 \\
ESI $=$ emotional-social intelligence. & & \\
\end{tabular}

Table 2. Difference in mean score of ESI questionnaire between male and female students $(N=127)$

\begin{tabular}{|c|c|c|c|c|c|}
\hline Variables & Male, mean (SD) & Female, mean (SD) & Mean difference & $t$-test & $p$-value ${ }^{*}$ \\
\hline Mean score of intrapersonal competencies & $68.88(9.16)$ & $70.63(5.77)$ & 1.75 & 1.31 & 0.19 \\
\hline Mean score of interpersonal competencies & $54.17(8.32)$ & $58.82(7.58)$ & 4.65 & 3.017 & $0.003^{*}$ \\
\hline Mean score adaptability & $36.48(5.62)$ & $37.97(5.98)$ & 0.49 & 1.38 & 0.17 \\
\hline Stress management & $43.41(4.94)$ & $44.30(8.01)$ & 0.89 & 0.66 & 0.51 \\
\hline General mood & $30.30(4.07)$ & $31.06(3.51)$ & 0.76 & 1.092 & 0.28 \\
\hline Mean score of ESI questionnaire & $233.27(27.07)$ & $242.79(24.08)$ & 9.52 & 1.397 & $0.04^{*}$ \\
\hline
\end{tabular}

Table 3. Mean score of subscale and total academic achievement scale by sex $(N=127)$

\begin{tabular}{|c|c|c|c|c|c|}
\hline Items & Male, mean (SD) & Female, mean (SD) & Mean difference & $t$-test & $p$-value ${ }^{*}$ \\
\hline Academic performance & $36.38(6.88)$ & $34.51(6.57)$ & 1.87 & 0.81 & 0.60 \\
\hline Extracurricular activities & $39.13(4.87)$ & $39.76(7.39)$ & 0.63 & 0.76 & 0.45 \\
\hline Student interaction & $37.21(6.64)$ & $38.22(8.49)$ & 1.01 & 0.92 & 0.12 \\
\hline Student behavior & $27.59(6.97)$ & $26.83(6.40)$ & 0.76 & 0.63 & 0.20 \\
\hline Student attendance & $25.63(7.10)$ & $25.95(6.04)$ & 0.32 & 0.91 & 0.78 \\
\hline Total academic achievement mean score & $165.94(19.90)$ & $165.27(27.67)$ & 1.79 & 0.84 & 0.46 \\
\hline
\end{tabular}




\section{Discussion}

It is believed that the application of the ESI concept in nursing education programmes helps students to deal with pressures related to their studies, and also improves their communication skills. ${ }^{[13]}$ Earlier studies have indicated an association between ESI and academic achievement. The aim of the present study was to examine the association between emotional intelligence and academic achievement in undergraduate nursing students at the College of Applied Medical Sciences, Saudi Arabia. The results identified an association between ESI and the demographic characteristics of participants, and recognised a correlation between academic achievement and level of ESI.

About two-thirds of the study sample were male, the mean age of the participants was 20.73 years, with most aged $>20$ years, and the majority of participants' parents had obtained higher education.

The demographic characteristics of participants in this study were different from those in earlier studies among nursing students. Jacob and Pavithran ${ }^{[14]}$ and Fallahzadeh ${ }^{[15]}$ studied the impact of ESI in nursing students, the majority of whom were female. The age of participating nursing students in our study was similar to that reported by Sinha et al ${ }^{[16]}$ and Moawed et al. ${ }^{[17]}$ With respect to parents' education, the data in the present study were similar to those in a study by Moawed et al. ${ }^{[17]}$ who carried out a comparative study of emotional intelligence skills of nursing students in Riyadh (Saudi Arabia) and Tanta (Egypt), and showed that most of the students' parents in Riyadh had high education levels.

The current study revealed that more than two-thirds of participants were of satisfactory ESI level ( $>60 \%$ of the total score). This may be due to the presence of more extracurricular activities and summer courses, which enhance and refresh abilities that help students improve their ESI. This emotional intelligence level may also be due to increased attention given to the affective and emotional domains during the teaching process. This result was similar to that reported by Manjusha et al. ${ }^{18]}$ on emotional intelligence and academic performance among nursing students, where $68.3 \%$ of assessed students had a satisfactory emotional intelligence level. The results are also in line with Sinha et al. ${ }^{[20]}$ who reported that $61 \%$ of assessed students had normal and high emotional intelligence $(46 \%$ had normal levels and 15\% had high levels).

The mean total ESI scores of male and female participants were 233.27 and 242.79, respectively, and this difference between male and female participants was statistically significant $(p<0.042)$. The interpersonal competencies score was significantly higher in female students $(p=0.003)$.

Earlier studies comparing ESI scores in male and female students reveal varying results. Fallahzadeh ${ }^{[15]}$ reported no statistically significant difference in total ESI scores between male and female students. Further, he reported that there was no significant difference between male and female students in the mean of all dimensions of ESI ( $p>0.05)$ except for the difference in mean score of adaptability scale. The findings of this study were supported by Saddki et al.$^{[19]}$ and Acebes-Sánchez, ${ }^{[20]}$ who reported that females had a significantly higher emotional intelligence score than males.

About two-thirds of the participants had a high level of self-reported academic achievement in the present study. This is possibly because most participants had a satisfactory emotional intelligence level. Our results support an earlier report by Manjusha et al. ${ }^{[18]}$ in which $69 \%$ of nursing students had good and very good levels of emotional intelligence and academic performance.
Regarding academic achievement and sex, results of this study showed that there was no significant correlation between the two, which supports the findings of earlier studies. Blackman et al. ${ }^{[21]}$ and Ugoji ${ }^{[22]}$ showed that there was no significant correlation between sex and academic achievement of students. Wan Chik et al. ${ }^{[23]}$ indicated that male students have lower academic performance than female students, as measured by grade point average. This may have been due to a difference in the percentage of male and female participants in their study.

The Pearson correlation test presented a positive correlation between the age of participants and the total score in ESI. The findings are in line with Carstensen et al., ${ }^{[24]}$ Snowden, ${ }^{[25]}$ Suleman et al., ${ }^{[26]}$ Nagar ${ }^{[27]}$ and Hamouda and $\mathrm{Al}$ Nagshabandi, ${ }^{[28]}$ who reported the presence of a significant positive relationship between age and ESI. This may be due to the fact that older adults are more skilled at regulating their emotions than younger adults, and that particular aspects of emotional intelligence may increase with age.

The education of participants' parents significantly affected participant's ESI scores, with high scores among participants whose parents had a high educational level. The result was similar to Haraluretal ${ }^{[29]}$ and Pant and Singh, ${ }^{[30]}$ who reported significant statistical differences in ESI scores based upon parents' education levels.

Our study revealed a positive correlation between emotional intelligence and academic achievement. Several studies support this result. Manjusha et al. ${ }^{[18]}$ and Kouchakzadeh et al..$^{[31]}$ also support a significant positive relationship between academic performance and emotional intelligence of nursing students. Similarly, Kumar et al. ${ }^{[32]}$ and Suleman et al. ${ }^{[26]}$ confirmed the strong positive relationship between emotional intelligence and academic success. The results of our study are also supported by a comprehensive quantitative review by Ranjbar et al. ${ }^{[33]}$ for all published studies on emotional intelligence and academic achievement in Iranian students, and a systemic review by Hanafi and Noor. ${ }^{[34]}$ ESI can be considered as a predictor for academic achievement level, as students with low emotional intelligence may have low concentration and show aggression in their relations and in dealing with their peers. They may also struggle to communicate their feelings to their colleagues. In contrast, students with higher levels of emotional intelligence are able to manage themselves better and communicate more effectively with their peers and teachers. This can assist them to improve self-motivation and effective communication skills, and help students become more confident learners.

The findings of our study contradict earlier reports by Shah et al. ${ }^{[35]}$ and Gilani et al. ${ }^{[36]}$ that show that academic achievement and ESI are negatively correlated. Our results are also different from those reported by Zirak and Ahmadian, ${ }^{[37]}$ which suggest an absence of a significant relationship between total emotional intelligence and academic achievement.

Our study results also indicated the presence of positive correlations between the five dimensions of the ESI questionnaire, including intrapersonal and interpersonal competencies, adaptability, stress management and general mood ( $r$ values $0.440,0.379,0.385,0.236$ and 0.407 , respectively). Our results are supported by Oyewunmi et al. ${ }^{[38]}$

\section{Conclusion}

Our results indicate an association between emotional intelligence and the academic achievement of nursing students. Nursing educators should create ESI-developing courses that can be taught by experts in the field at college and university level, and workshops on strategies to boost the ESI 
of learners. Emotional intelligence should be part of the educational plan for students, and students should be provided with workshops to boost their ESI. This study should be replicated with a larger sample size and in a different setting to further confirm its findings.

\section{Declaration. None.}

Acknowledgements. None.

Author contributions. Equal contributions.

Funding. None.

Conflicts of interest. None.

1. Banat BYI, Rimawi OT. The impact of emotional intelligence on academic achievement: A case study of Al-Qud University students. Int Humanities Studies 2014;2(1):12-40.

2. Plucker JA, Peters SJ, 2020. Excellence gaps in education: Expanding opportunities for talented students. Cambridge, MA: Harvard Education Press, 2020

3. Mohamadirizi S, Kohan S, Shafei F, Mohamadirizi S. The relationship between clinical competence and clinical self-efficacy among nursing and midwifery students. Int J Pediatr 2015;3(6.2):1117-1123. https://doi.org/10.22038/ijp.2015.5222 4. Rozell EJ, Pettijohn CE, Parker RS. An empirical evaluation of emotional intelligence. J Manag Dev 2002;21(4):272-289. https://doi.org/10.1108/02621710210430272

5. Farooq MA. Effect of emotional intelligence on academic performance. Doctoral dissertation. Karachi University of Karachi, 2003

6. Adeyemo DA. Moderating influence of emotional intelligence on the link between academic self-efficacy and achievement of university students. Psychol Dev Soc 2007;19(2):199-213. https://doi.org/10.1177\% 2F097133360701900204

7. Sünbül AM, Aslan Y. The relationship between emotional intelligence and achievement among 1st and 4th grade faculty students. Sci Bull Edu Sci Ser 2008;2:27-42.

8. Nwadinigwe IP, Azuka-Obieke U. The impact of emotional intelligence on academic achievement of senio secondary school students in Lagos, Nigeria. J Emer Trends Edu Res Policy Stud 2012;3(4):395-401.

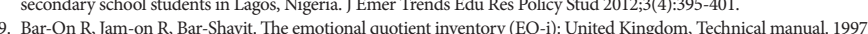

9. Bar-On R, Jam-on R, Bar-Shavit. The emotional quotient inventory (EQ-i): United Kingdom, Technical manual. 1997,
10. Zimmerman BJ, Schunk DH (editors.) Self-Regulated Learning and Academic Achievement: Theoretical Perspectives. Abingdon: Routledge, 2001.
Pimmerman B], Schunk DH (editors.)

11. Sun W, Chou CP, Stacy AW, Unger J, Gallaher P. SAS and SPSS macros to calculate standardized Cronbach' alpha using the upper bound of the phi coefficient for dichotomous items. Behav Res Methods 2007;39(1):71-81 2. Tavakol M, Dennick R. Making sense of Cronbach's alpha. Int J Med Edu 2011;2:53-55

3. Barkhordari M, Rostambeygi P. Emotional intelligence in nursing students. J Adv Med Prof 2013;1(2):46-50.

14. Jacob W, Pavithran S. Correlational study on emotional intelligence and academic performance of nursing students in a selected college of nursing, Kochi. Int J Pharm Sci Health Care 2015;4(5);30-41.

15. Fallahzadeh H. 2011. The relationship between emotional intelligence and academic achievement in medical science students in Iran. Procedia Social Behav Sci 2011;30:1461-1466.

16. Sinha B, Bachracharya R, Pandey S, Sobhita K, Koirala S, Kushwaha MP. Emotional intelligence among undergraduate nursing students. Int J Sci Res Pub 2017;7(12):622-629.

17. Moawed S, Gemeay EM, Elsayes H. Emotional intelligence among nursing students: A comparative study. Int J Novel Res Healthcare Nur 2017;4(1):359-369.

18. Manjusha S, Soja SL, Usha VK. Emotional intelligence and academic performance among nursing students. Int J Curr Res 2017;9(3):48116-48118.
19. Saddki N, Sukerman N, Mohamad D. Association between emotional intelligence and perceived stress in undergraduate dental students. Malay J Med Sci 2017;24(1):59. https://doi.org/10.21315\%2Fmjms2017.24.1.7

20. Acebes-Sánchez J, Diez-Vega I, Esteban-Gonzalo S, Rodriguez-Romo G. Physical activity and emotion intelligence among undergraduate students: A correlational study. BMC Public Health 2019;19(1):1241. https:/ doi.org/10.1186/s12889-019-7576-5

21. Blackman I, Hall M, Darmawan I. Undergraduate nurse variables that predict academic achievement and clinical competence in nursing. Int Edu J 2007;8(2):222-236.

22. Ugoji FN. The impact of counseling on the academic performance of secondary school students. Africa J Int Discip Studies 2008;8(2):67-69.

23. Wan Chik WZ, Salamonson Y, Everett B, et al. Gender difference in academic performance of nursing students in a Malaysian university college. Int Nur Rev 2012;59(3):387-393. https://doi.org/10.1111/j.1466-7657.2012.00989.x

24. Carstensen LL, Turan B, Scheibe S, et al. Emotional experience improves with age: Evidence based on over 10 . Carstensen LL, Turan B, Scheibe S, et al. Emotional experience improves with age: Evidence ba
years of experience sampling. Psychol Aging 2011;26(1):21. https://doi.org/10.1037\%2Fa0021285

25. Snowden A, Stenhouse R, Young I, Carver H, Carver F, Brown N. The relationship between emotional intelligence, previous caring experience and mindfulness in student nurses and midwives: A cross-sectional analysis. Nurse Educ Today 2015;35(1):152-158. https://doi.org/10.1016/j.nedt.2014.09.004

26. Suleman Q, Hussain I, Syed MA, Parveen R, Lodhi IS, Mahmood Z. Association between emotional intelligence and academic success among undergraduates: A cross-sectional study in KUST, Pakistan. PloS On 2019;14(7):e0219468. https://doi.org/10.1371/journal.pone.0219468

27. Nagar M. Role of demographic factors in emotional intelligence: An empirical study of bank managers. Indian Comm Manag Studies 2017;8(3);26. https://doi.org/10.18843/ijcms/v8i3/04

28. Hamouda GMH, Al Nagshabandi EAH. The perception of emotional intelligence self-assessment among nursing students. Am J Nur 2018;7(5):173-177. https://doi.org/10.11648/J.AJNS.20180705.13

29. Haralur SB, Majeed MI, Afzal M, Chaturvedi S. Association of sociodemographic factors and emotional intelligence with academic performance in clinical and preclinical dental courses. Nigerian I Clin Prac 2019;22(8):1109. https://doi.org/10.4103/njcp.njcp_37_19

30. Pant K, Singh R. Educational status of parents as a predictor of social and emotional maturity of adolescents. Int J Environ Ecol Fam Urban Studies 2017;1:53-64.

31. Kouchakzadeh TS, Namazi A, Alizadeh SH. The correlation between emotional intelligence and academic Kouchakzadeh TS, Namazi A, Alizadeh SH. The correlation between emotional intelligence and academic
achievement on nursing and midwifery students. Iran J Nurs 2016;29(102);1-10. https://doi.org/10.29252 achievement on nursing and midwifery students. Iran J Nurs 2016;29(102);1-10. https://doi.org/10.29252/ ijn.29.102.

32. Kumar A, Chowdhury SR, Panwar M, Kosala M. Assessment of association between emotional intelligence and academic achievement among Indian nursing students. Galore Int J Health Sci Res 2016;1(1):10-17

33. Ranjbar H, Khademi SH, Areshtanab HN. The relation between academic achievement and emotiona intelligence in Iranian students: A meta-analysis. Acta Facultatis Medicae Naissensis 2017;34(1):65-76. https:/ doi.org/10.1515/afmnai-2017-0008

34. Hanafi Z, NoorF. Relationship between emotional intelligence and academic achievement in emerging adults A systematic review. Int JAcad Res Business Social Sci 2016;6(6):268-290. https://doi.org/10.6007/IJARBSS/v6i6/2197

35. Shah CJ, Sanisara M, Mehta HB, Vaghela HM. The relationship between emotional intelligence and academic achievement in medical undergraduates. Int J Res Med Sci 2014;2(1):59-61. https://doi.org/10.5455/2320-6012 ijrms20140211

36. Gilani N, Waheed SA, Saleem K, Shoukat L. Do emotions affect academic success in adulthood relationship between postgraduate students' trait emotional intelligence success. AYER, 2015;2:37-44.

37. Zirak M, Ahmadian E. Relationship between emotional intelligence \& academic achievement emphasizing Zirak M, Ahmadian E. Relationship between emotional intelligence \& academic achievement emph
creative thinking. Mediterr J Social Sci 2015;6(5):561-561. https://doi.org/10.5901/mjss.2015.v6n5s2p561

38. Oyewunmi AE, Osibanjo AO, Adeniij AA. Emotional intelligence and academic performance of undergraduates Correlations, implications and interventions. Mediterr J Social Sci 2016;7(1):509. https://doi.org/10.5901/ mjss.2016.v7n1p509

Accepted 13 July 2020. 